\title{
Influence of Hydrogen Ion Concentration on the Tissue Respiration of Mouse and Rabbit in Vitro, Attention being Paid to the Buffer Potency of the Tissue.*
}

By

\author{
Kentarô Nomura.
}

(野 村慧太 郳)

(From the Institute of Physiology, Director: Prof.

S. Kodama, Kumamoto Medical College.)

In the former investigation ${ }^{1)}$ we studied the influence of hydrogen ion concentration within the range 7.44-5.50 on oxygen consumption of liver tissue of mouse by Warburg's first method (1923).2?

In the present investigation we repeated the experiment, but in this case attention was paid specially to a possible buffer action of the tissue, by which the latter tries to guard the medium against change of its hydrogen ion concentration.

Okabe and Koda ma $\mathrm{a}^{3)}$ have found that the kidney tissue, both cortical and medullar, especially the latter, as well as the liver tissue of rabbit, show that the more the hydrogen ion concentration of the medium is increased, the greater the carbon dioxide output.

The production of the carbon dioxide results in increasing of the hydrogen ion concentration of the medium, that is, the former seems to act against lowering of the latter. Okabe and Kodama did not, however, examine actually the medium of the tissue with regard to possible changing of the hydrogen ion concentration.

We know that the hydrogen ion concentration of blood in animal body is protected very finely against change of the normal range

* The essentials of this paper were read before the thirteenth annual meeting of the Japanese Physiological Society, held at Tôkyô, April 1934 (Jap. J. Med. Sci., III. Biophysics $\left.1934,3,260^{*}\right)$.

1) Nom u ra, K., Tohoku J. Exp. Med., 1936, 30, 8.

2) Warburg, O., Biochem. Z., 1923, 142, 317.

3) Oka be, T. and S. Ko d a ma, Tohoku J. Exp. Med., 1934, 23, 273. 
in different ways. ${ }^{4}$ On a possible buffer action, by which tissues would regulate the reaction of the surrounding medium within a narrower range, relatively few investigations are known to us.

Fleis $\mathrm{ch}^{5}$ has found that the blood, after having perfused through both legs of rabbit, was changed towards the acid side, and he has attributed the fact to acid metabolic products of the tissue, without any consideration of the buffer action of the tissue.

Atzler and Lehmann $n^{6}$ seem to be the first who have assumed an existence of the $\left[\mathrm{H}^{+}\right]$-regulating potency of the tissue, and proved it experimentally by frog perfusion. Later they proved the fact as true also with warm blooded animals (rabbit), ${ }^{\text {?) }}$ and tried to express the buffer potency of the tissue mathematically, with consideration of the mechanisms of the action. Findings of $\mathrm{Katz}$ and $\mathrm{Banus}^{8)}$ with isolated gastrocnemius of dog contradicted the above mentioned experiment. They attributed the non-existence of the buffer action of the muscle preparation to non-occurrence of the exchange of chloride or alkaline radicals between the blood and the muscle at perfusion of the latter with blood acidified with $\mathrm{HCl}$.

More recently $\mathrm{Nagakaw} \mathrm{a}^{9)}$ found the buffer potency of rabbit uterus by perfusion experiment, which has, he believed, some relationship with vegetative nervous system. Later he found also that the buffer potency of rabbit uterus depended on the periodical state of the organ, and that that of the young uterus was also changed by injecting perfused fluid of ovarium at various stadia. ${ }^{10)} \mathrm{Le} \mathrm{e}^{11}$ found also the buffer potency of toad kidney by experiment similar to that of Nagakawa.

From the experiments above cited except that of $\mathrm{Katz}$ and $\mathrm{Ba}-$ $n$ us existence of the $\left[\mathrm{H}^{+}\right]$regulating influence of the tissue on the surrounding medium seems to be without doubt. How the result of our experiment was, is now to be stated in the following lines.

\section{Methods.}

Tissues used were of mouse liver and rabbit kidney, cortical and medullar separately.

4) Gollwitzer-Meier, Kl, Bethe-Bergmann's Handbuch der normalen and pathologiachen Physiologie, XVI-I, 1071-1159, Berlin, 1930.

5) Fle is ch, A., Z. f. allgem. Physiol., 1921, 19, 309.

6) Atzler, E., and G. Leh ma n n, Pflügers Arch., 1921, 193, 466.

7) Atzler, E., and G. Le h man n, Pflügers Arch., 1922, 197, 206.

8) K atz, L.N., and M.G. Banus, Am.J. of Physiol., 1927, 81, 628.

9) N a g a a wa, K., Nippon Yakubutugaku Z., 1934, 18, 57; Jap. J. of Med. Sci , Trans., IV, Pharmacol, 1934, 8, 70*.

10) Nagak a wa, K., Nippon Yakubutugaku Z., 1935, 20,61.

11) Lee, Y.S., ibid., 1935, 20, 57. 
Investigation of oxygen consumption only was made by Warburg's first method, ${ }^{2)}$ that of both oxygen consumption and carbon dioxide output by his second modified method. ${ }^{12}$ General procedures of our former reports were followed. Manometric measurements were done every 20 minutes during two or three hours. Ringer's solution and its hydrogen ion concentration were prepared for the first series of the experiment as in our previous report, ${ }^{1)}$ and for the second series the Ringer's solution as in our former papers. ${ }^{13)}$ The hydrogen ion concentration of this Ringer was prepared according to $\mathrm{H}$ as selbal c h's principle ${ }^{14)}$ by mixing $\mathrm{NaHCO}_{3}$-solution with $\mathrm{CO}_{2}$ gas of suitable tension (as to the actual arrangement, see the experimental part).

The hydrogen ion concentration used for the experiment of the Ringer's solution was at every experiment potentiometrically measured with the gas chain method before and after the manometric experiment, also that of the Ringer used for the thermo-barometric control manometer. In the case of the second series, the hydrogen gas used for the electrode contained $\mathrm{CO}_{2}$-gas of the tension, which was kept in the respiratory vessel, the tension after the manometric experiment being regarded as the same as that before the experiment.

The potentiometric value of $p \mathrm{H}$ had to receive inconsistency with the calculated one, because the measurement of $\mathrm{CO}_{\mathrm{g}}$-tension by Haldane apparatus had to suffer $0.2 \%$ error, and so it was quite difficult to prepare the tension in the hydrogen gas electrode in sufficient agreement.

In this way we investigated as to whether the tissue would have acted to regulate the hydrogen ion concentration of the medium, which had not been normal for it.

\section{EXPERIMENTS.}

\section{Oxygen Consumption of the Tissue.}

Three kinds of hydrogen ion concentrations were prepared in quite the same way as in the previous report. 1) To $100 \mathrm{cc}$. of the normal Ringer's solution was added 2 cc. of the phosphate mixtures, the ratios of mixing the primary and secondary being a) $1: 0$, b) $3: 7$ and c) $0: 1$. At each experiment, the hydrogen ion concentration of the

12) Warburg, O., Bjochem. Z., 1924, 152, 51.

13) Nomura, K., Cytologia, 1933, 4, 258.

14) H a sselbaleh, K.A., Biochem, Z., 1917, 78, 112. 
so prepared Ringer's solution was potentiometrically measured. The means of $p \mathrm{H}$ were 5.501 (a), 6.921 (b) and 7.437 (c) respectively.

\section{A. Liver tissue of mouse.}

Results are shown in Table 1.

Table 1.

Oxygen consumption (Qo) of liver tissue of mouse in various $p \mathrm{H}-R$ Ringer's solution buffered by phosphate mixture $(a=5.5, b=6.9, c=7.4)$.

(5. X-9. XII. 1933)

\begin{tabular}{|c|c|c|c|c|c|c|c|c|c|c|c|c|c|}
\hline \multirow{2}{*}{ No. } & \multirow{2}{*}{$\begin{array}{c}\text { Kind } \\
\text { of } \\
p \mathrm{H}\end{array}$} & \multicolumn{12}{|c|}{ Time (min.) after beginning of observation and Qo } \\
\hline & & $\begin{array}{c}I \\
20\end{array}$ & $\begin{array}{l}\text { II } \\
20\end{array}$ & $\begin{array}{c}\text { III } \\
20\end{array}$ & $\begin{array}{c}I \\
\text { mean }\end{array}$ & $\begin{array}{l}\text { IV } \\
20\end{array}$ & $\begin{array}{c}\mathrm{V} \\
20\end{array}$ & $\begin{array}{l}\text { VI } \\
20\end{array}$ & $\underset{\text { mean }}{\text { II }}$ & $\begin{array}{c}\text { VII } \\
20\end{array}$ & $\begin{array}{c}\text { VIII } \\
20\end{array}$ & $\begin{array}{l}\text { IX } \\
20\end{array}$ & $\underset{\text { mean }}{\text { III }}$ \\
\hline 1 & $\begin{array}{l}a \\
b \\
c\end{array}$ & $\begin{array}{l}7.4 \\
8.9 \\
9.9\end{array}$ & $\begin{array}{r}5.2 \\
13.0 \\
14.1\end{array}$ & $\begin{array}{r}0.7 \\
12.4 \\
14.0\end{array}$ & $\begin{array}{r}4.4 \\
11.4 \\
12.7\end{array}$ & $\begin{array}{r}5.8 \\
10.3 \\
10.1\end{array}$ & $\begin{array}{l}0.7 \\
7.5 \\
8.2\end{array}$ & $\begin{array}{l}1.7 \\
6.2 \\
6.5\end{array}$ & $\begin{array}{l}2.7 \\
8.0 \\
8.3\end{array}$ & $\begin{array}{l}0.4 \\
7.6 \\
8.7\end{array}$ & $\begin{array}{r}+1.4 \\
6.6 \\
8.1\end{array}$ & $\begin{array}{l}4.5 \\
7.0 \\
9.0\end{array}$ & $\begin{array}{l}1.2 \\
7.1 \\
8.6\end{array}$ \\
\hline 2 & $\begin{array}{l}a \\
b \\
c\end{array}$ & $\begin{array}{r}7.4 \\
11.0 \\
13.8\end{array}$ & $\begin{array}{r}8.3 \\
9.9 \\
14.2\end{array}$ & $\begin{array}{r}8.1 \\
13.6 \\
18.7\end{array}$ & $\begin{array}{r}7.9 \\
11.5 \\
15.6\end{array}$ & $\begin{array}{r}7.6 \\
7.4 \\
11.1\end{array}$ & $\begin{array}{r}6.5 \\
10.0 \\
11.9\end{array}$ & $\begin{array}{r}6.1 \\
5.8 \\
15.2\end{array}$ & $\begin{array}{r}6.7 \\
7.7 \\
12.7\end{array}$ & $\begin{array}{l}5.6 \\
6.2 \\
9.7\end{array}$ & $\begin{array}{r}5.2 \\
3.7 \\
13.7\end{array}$ & $\begin{array}{l}3.0 \\
5.3 \\
7.9\end{array}$ & $\begin{array}{r}4.6 \\
5.1 \\
10.4\end{array}$ \\
\hline $\mathbf{3}$ & $\begin{array}{l}a \\
b \\
c\end{array}$ & $\begin{array}{l}7.5 \\
8.6 \\
8.6\end{array}$ & $\begin{array}{l}4.8 \\
8.6 \\
8.4\end{array}$ & $\begin{array}{l}4.8 \\
8.9 \\
9.4\end{array}$ & $\begin{array}{l}5.7 \\
8.7 \\
8.8\end{array}$ & $\begin{array}{r}2.6 \\
7.9 \\
11.2\end{array}$ & $\begin{array}{l}2.2 \\
7.8 \\
5.2\end{array}$ & $\begin{array}{r}1.2 \\
10.0 \\
12.7\end{array}$ & $\begin{array}{l}2.0 \\
8.6 \\
9.7\end{array}$ & $\begin{array}{l}0.3 \\
6.7 \\
7.7\end{array}$ & $\begin{array}{l}0.3 \\
6.3 \\
6.5\end{array}$ & $\begin{array}{r}+1.7 \\
7.3 \\
8.2\end{array}$ & $\begin{array}{r}0.4 \\
6.8 \\
7.5\end{array}$ \\
\hline 4 & $\begin{array}{l}a \\
b \\
c\end{array}$ & $\begin{array}{l}5.6 \\
7.5 \\
8.1\end{array}$ & $\begin{array}{l}4.7 \\
6.8 \\
7.3\end{array}$ & $\begin{array}{l}4.1 \\
6.5 \\
8.7\end{array}$ & $\begin{array}{l}4.8 \\
6.9 \\
8.0\end{array}$ & $\begin{array}{l}4.5 \\
7.3 \\
8.0\end{array}$ & $\begin{array}{l}1.6 \\
5.3 \\
6.9\end{array}$ & $\begin{array}{r}+0.3 \\
3.4 \\
2.9\end{array}$ & $\begin{array}{l}1.9 \\
5.3 \\
5.9\end{array}$ & $\begin{array}{l}2.3 \\
4.7 \\
4.0\end{array}$ & $\begin{array}{l}1.6 \\
5.6 \\
4.6\end{array}$ & $\begin{array}{l}0.1 \\
5.1 \\
6.7\end{array}$ & $\begin{array}{l}1.3 \\
5.1 \\
5.1\end{array}$ \\
\hline 5 & $\begin{array}{l}a \\
b \\
c\end{array}$ & $\begin{array}{l}8.6 \\
4.8 \\
3.8\end{array}$ & $\begin{array}{l}2.1 \\
6.8 \\
8.7\end{array}$ & $\begin{array}{r}+0.1 \\
5.7 \\
7.9\end{array}$ & $\begin{array}{l}3.5 \\
5.8 \\
6.8\end{array}$ & $\begin{array}{r}+0.9 \\
5.0 \\
8.7\end{array}$ & $\begin{array}{l}0.9 \\
4.4 \\
7.4\end{array}$ & $\begin{array}{l}1.0 \\
4.1 \\
6.5\end{array}$ & $\begin{array}{l}0.3 \\
4.5 \\
7.5\end{array}$ & $\begin{array}{l}1.4 \\
4.2 \\
7.2\end{array}$ & $\begin{array}{l}1.3 \\
5.2 \\
7.6\end{array}$ & $\begin{array}{l}2.7 \\
4.7 \\
7.2\end{array}$ & $\begin{array}{l}1.8 \\
4.7 \\
7.3\end{array}$ \\
\hline 6 & $\begin{array}{l}a \\
b \\
c\end{array}$ & $\begin{array}{r}3.4 \\
12.7 \\
20.2\end{array}$ & $\begin{array}{r}5.6 \\
8.7 \\
12.3\end{array}$ & $\begin{array}{r}3.9 \\
8.0 \\
11.2\end{array}$ & $\begin{array}{r}4.3 \\
9.8 \\
14.6\end{array}$ & $\begin{array}{l}2.2 \\
5.8 \\
8.6\end{array}$ & $\begin{array}{l}2.1 \\
5.2 \\
5.7\end{array}$ & $\begin{array}{l}2.1 \\
5.1 \\
7.6\end{array}$ & $\begin{array}{l}2.1 \\
5.3 \\
7.2\end{array}$ & $\begin{array}{l}0.5 \\
3.5 \\
5.8\end{array}$ & $\begin{array}{l}0.7 \\
1.1 \\
\mathbf{2 . 9}\end{array}$ & $\begin{array}{l}1.6 \\
1.8 \\
1.1\end{array}$ & $\begin{array}{l}0.9 \\
2.1 \\
\mathbf{3} .3\end{array}$ \\
\hline 7 & $\begin{array}{l}a \\
b \\
c\end{array}$ & $\begin{array}{r}10.2 \\
8.6 \\
17.0\end{array}$ & $\begin{array}{l}6.9 \\
8.9 \\
5.6\end{array}$ & $\begin{array}{l}4.8 \\
6.3 \\
6.8\end{array}$ & $\begin{array}{l}7.3 \\
7.9 \\
9.8\end{array}$ & $\begin{array}{r}5.8 \\
9.6 \\
11.3\end{array}$ & $\begin{array}{l}3.0 \\
4.5 \\
6.3\end{array}$ & $\begin{array}{l}2.7 \\
5.8 \\
7.3\end{array}$ & $\begin{array}{l}3.8 \\
6.6 \\
8.3\end{array}$ & $\begin{array}{l}1.8 \\
5.2 \\
9.2\end{array}$ & $\begin{array}{l}2.7 \\
4.4 \\
6.2\end{array}$ & $\begin{array}{r}2.7 \\
6.7 \\
12.2\end{array}$ & $\begin{array}{l}2.4 \\
5.8 \\
9.2\end{array}$ \\
\hline 8 & $\begin{array}{l}a \\
b \\
c\end{array}$ & $\begin{array}{l}7.0 \\
8.3 \\
7.0\end{array}$ & $\begin{array}{l}5.1 \\
7.4 \\
7.4\end{array}$ & $\begin{array}{l}4.1 \\
6.5 \\
6.0\end{array}$ & $\begin{array}{l}5.4 \\
7.4 \\
6.8\end{array}$ & $\begin{array}{l}2.6 \\
6.5 \\
9.2\end{array}$ & $\begin{array}{l}3.1 \\
5.8 \\
6.0\end{array}$ & $\begin{array}{l}2.6 \\
7.2 \\
8.9\end{array}$ & $\begin{array}{l}2.8 \\
6.5 \\
8.0\end{array}$ & $\begin{array}{l}2.1 \\
3.6 \\
4.1\end{array}$ & $\begin{array}{l}1.5 \\
5.4 \\
4.6\end{array}$ & $\begin{array}{l}2.4 \\
3.1 \\
4.4\end{array}$ & $\begin{array}{l}2.0 \\
4.0 \\
4.4\end{array}$ \\
\hline 9 & $\begin{array}{l}a \\
b \\
c\end{array}$ & $\begin{array}{r}7.2 \\
11.1 \\
10.3\end{array}$ & $\begin{array}{l}3.8 \\
1.0 \\
3.3\end{array}$ & $\begin{array}{r}2.1 \\
10.4 \\
12.9\end{array}$ & $\begin{array}{l}4.4 \\
7.5 \\
8.8\end{array}$ & $\begin{array}{r}+0.5 \\
3.2 \\
4.4\end{array}$ & $\begin{array}{r}+1.1 \\
7.8 \\
9.1\end{array}$ & $\begin{array}{r}0.8 \\
2.6 \\
6.1\end{array}$ & $\begin{array}{r}+0.8 \\
4.5 \\
6.5\end{array}$ & $\begin{array}{r}+1.7 \\
6.1 \\
7.5\end{array}$ & $\begin{array}{r}+1.4 \\
4.2 \\
7.7\end{array}$ & $\begin{array}{r}+2.5 \\
3.2 \\
5.3\end{array}$ & $\begin{array}{r}+1.9 \\
4.5 \\
6.8\end{array}$ \\
\hline 10 & $\begin{array}{l}a \\
b \\
c\end{array}$ & $\begin{array}{l}6.9 \\
7.0 \\
6.7\end{array}$ & $\begin{array}{r}7.2 \\
10.3 \\
13.0\end{array}$ & $\begin{array}{l}8.0 \\
7.1 \\
5.7\end{array}$ & $\begin{array}{l}7.4 \\
8.1 \\
8.5\end{array}$ & $\begin{array}{l}4.2 \\
6.2 \\
8.2\end{array}$ & $\begin{array}{l}3.6 \\
6.0 \\
5.3\end{array}$ & $\begin{array}{l}3.7 \\
6.0 \\
7.3\end{array}$ & $\begin{array}{l}3.8 \\
6.1 \\
6.9\end{array}$ & $\begin{array}{l}3.2 \\
5.9 \\
6.5\end{array}$ & $\begin{array}{l}2.3 \\
4.0 \\
4.7\end{array}$ & $\begin{array}{l}3.6 \\
3.5 \\
4.2\end{array}$ & $\begin{array}{l}3.0 \\
4.5 \\
5.1\end{array}$ \\
\hline Mean & b & $\begin{array}{r}7.1 \\
\pm 0.4 \\
8.9 \\
\pm 0.5 \\
10.5 \\
\pm 1.1\end{array}$ & $\begin{array}{r}5.4 \\
\pm 0.4 \\
8.1 \\
\pm 0.7 \\
9.4 \\
\pm 0.8\end{array}$ & $\begin{array}{r}4.1 \\
\pm 0.6 \\
8.5 \\
\pm 0.6 \\
10.1 \\
\pm 0.9\end{array}$ & $\begin{array}{r}5.5 \\
\pm 0.3 \\
8.5 \\
\pm 0.4 \\
10.0 \\
\pm 0.7\end{array}$ & $\begin{array}{r}3.4 \\
\pm 0.3 \\
6.9 \\
\pm 0.4 \\
9.1 \\
\pm 0.4\end{array}$ & $\begin{array}{r}2.3 \\
\pm 0.4 \\
6.4 \\
\pm 0.4 \\
7.2 \\
\pm 0.4\end{array}$ & $\begin{array}{r}2.0 \\
\pm 0.4 \\
5.6 \\
\pm 0.4 \\
8.1 \\
\pm 0.7\end{array}$ & $\begin{array}{r}2.6 \\
\pm 0.4 \\
6.3 \\
\pm 0.3 \\
8.1 \\
\pm 0.4\end{array}$ & $\begin{array}{r}1.6 \\
\pm 0.3 \\
5.5 \\
\pm 0.3 \\
7.0 \\
\pm 0.4\end{array}$ & $\begin{array}{r}1.3 \\
\pm 0.3 \\
4.7 \\
\pm 0.3 \\
6.7 \\
\pm 0.6\end{array}$ & $\begin{array}{r}1.6 \\
\pm 0.3 \\
4.8 \\
\pm 0.4 \\
6.6 \\
\pm 0.7\end{array}$ & $\begin{array}{r}1.5 \\
\pm 0.3 \\
5.0 \\
\pm 0.3 \\
6.8 \\
\pm 0.5\end{array}$ \\
\hline
\end{tabular}


A few experiments showed positive values of Qo, instead of negative, which is, naturally a result of the incompleteness of the experimental technique or method. For calculation of the mean value they are taken as such, not as zero as in the case of the previous reports.

The oxygen consumption (Qo) was the greatest at $p H$ 7.437, at 6.921 the next greatest, and at 5.501 the least, that is, the greater the $p H$ was, the greater the consumption was, within the range experimented with.

\section{Table 2.}

$p \mathrm{H}$ of Ringer's solution before and after manometric experiment of Table 1.

\begin{tabular}{|c|c|c|c|c|c|c|}
\hline \multirow{2}{*}{ No. } & \multicolumn{2}{|c|}{$\mathbf{a}$} & \multicolumn{2}{|c|}{$\mathbf{b}$} & \multicolumn{2}{|c|}{ c } \\
\hline & before & after & before & after & before & after \\
\hline 1 & 5.476 & 5.635 & 6.940 & 6.501 & 7.431 & 7.041 \\
\hline 2 & 5.676 & 5.622 & 7.034 & 6.626 & 7.377 & 6.763 \\
\hline 3 & 5.823 & 6.513 & 6.934 & 6.886 & 7.240 & 7.175 \\
\hline 4 & 5.727 & 6.309 & 6.885 & 6.760 & 7.504 & 7.117 \\
\hline 5 & 5.492 & 5.687 & 6.869 & 6.025 & 7.367 & 6.148 \\
\hline 6 & 5.318 & 5.618 & 6.872 & 6.394 & 7.503 & 6.874 \\
\hline 7 & 5.171 & 5.561 & 7.015 & 6.839 & 7.429 & 6.987 \\
\hline 8 & 5.654 & 5.912 & 6.899 & 6.780 & 7.505 & 7.092 \\
\hline 9 & 5.315 & 5.907 & 6.809 & 6.663 & 7.432 & 7.376 \\
\hline 10 & 5.457 & 5.794 & 6.957 & 7.333 & 7.590 & 7.468 \\
\hline Mean & 5.501 & 5.856 & 6.921 & 6.681 & 7.437 & 7.004 \\
\hline
\end{tabular}

The $p \mathrm{H}$ of the medium after the manometric measurement was potentiometrically measured as quickly as possible and was found as means to be 5.856 (a) for original $5.501,6.681$ (b) for 6.921 , and 7.004 (c) for 7.437. That is, the acid medium became somewhat basic, and the basic ones more acid (Table 2).

\section{$B_{1}$. Kidney tissue of rabbit.}

Rabbit kidney was divided into the cortical and the medullar tissue, and on each tissue the oxygen consumption was measured in

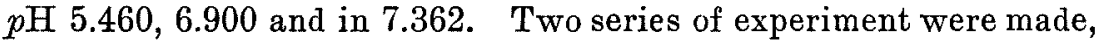
one with $1 \mathrm{n}$ sulphuric acid in side receptacle to absorb ammonia gas, which might escape from the liquid medium into the gaseous space. ${ }^{15}$,

The results are shown in Tables 3 and 4 .

15) Okabe, T., Reports from the Institute of Physiology, Kumamoto Medical College, 1934, No. 1 . 
Table 3.

Oxygen consumption (Qo) of medullar tissue of rabbit kidney in various $p \mathrm{H}$ Ringer's solution buffered by phosphate mixture $(a=5.5, b=6.9, c=7.4)$.

(10. XII. 1933-3. II. 1934)

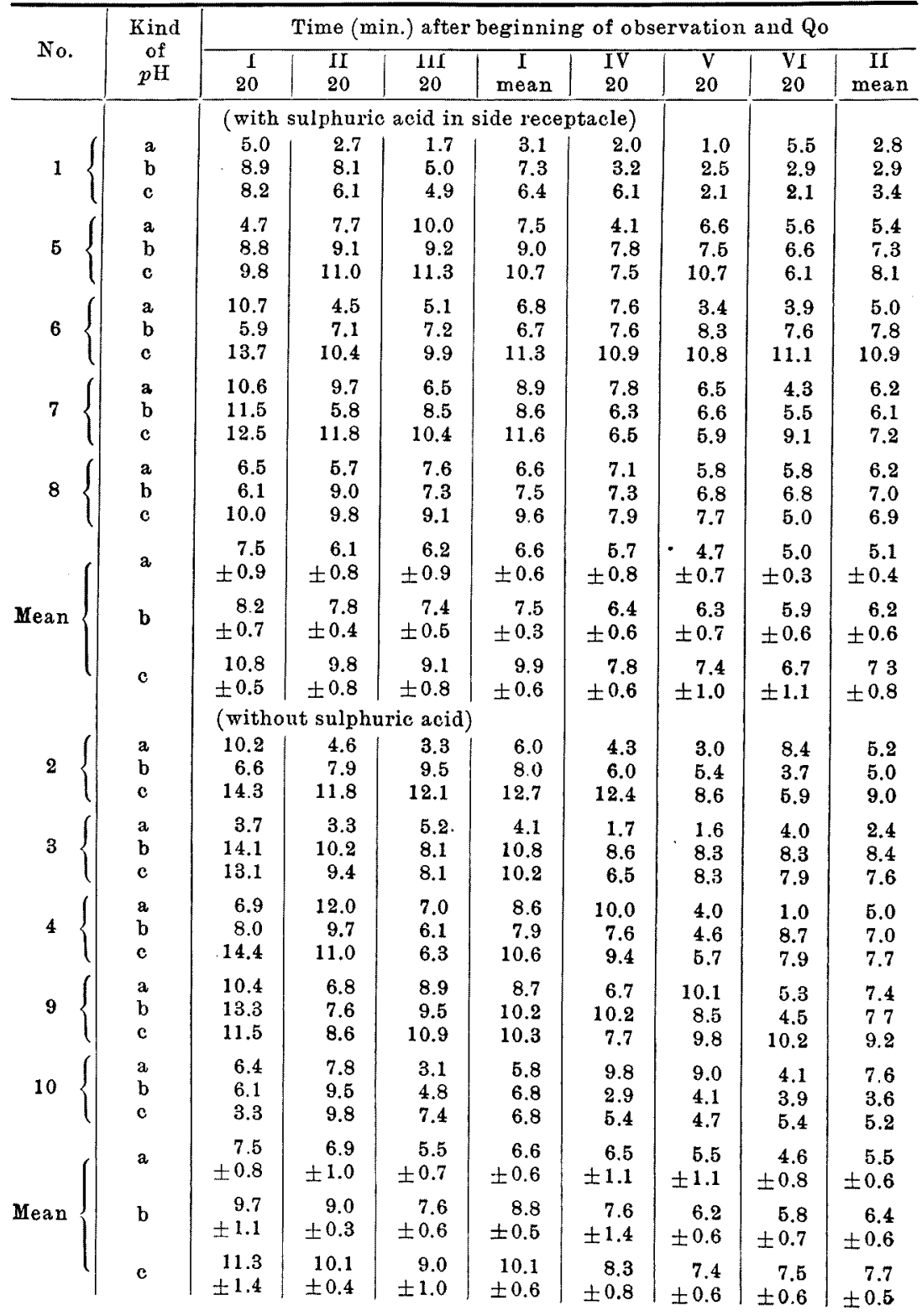


Table 4.

Oxygen consumption (Qo) of cortical tissue of rabbit kidney in various $p \mathrm{H}$ Ringer's solution buffered by phosphate mixture $(a=5.5, b=6.9, c=7.4)$.

(10. XII. 1933-3. II. 1934)

\begin{tabular}{|c|c|c|c|c|c|c|c|c|c|}
\hline \multirow{2}{*}{ No. } & \multirow{2}{*}{$\begin{array}{c}\text { Kind } \\
\text { of } \\
p \mathrm{H}\end{array}$} & \multicolumn{8}{|c|}{ Time (min.) after beginning of observation and Qo } \\
\hline & & $\begin{array}{c}\text { I } \\
20 \\
\end{array}$ & $\begin{array}{l}\text { II } \\
20 \\
\end{array}$ & $\begin{array}{l}\text { III } \\
20 \\
\end{array}$ & $\begin{array}{c}\mathrm{I} \\
\text { mean }\end{array}$ & $\begin{array}{l}\text { IV } \\
20 \\
\end{array}$ & $\begin{array}{c}V \\
20 \\
\end{array}$ & $\begin{array}{l}\text { VI } \\
20 \\
\end{array}$ & $\begin{array}{c}\text { II } \\
\text { mean }\end{array}$ \\
\hline 2 & $\begin{array}{l}a \\
b \\
c\end{array}$ & $\begin{array}{c}\text { (with } \\
10.5 \\
12.6 \\
19.6\end{array}$ & $\begin{array}{c}\text { Iphuri } \\
7.2 \\
8.0 \\
7.5\end{array}$ & $\begin{array}{r}\text { icid in } \\
7.1 \\
8.0 \\
15.8\end{array}$ & $\begin{array}{r}\text { de rec } \\
8.3 \\
9.5 \\
14.3\end{array}$ & $\begin{array}{r}\text { tacle) } \\
5.3 \\
5.1 \\
8.5\end{array}$ & $\begin{array}{l}8.3 \\
8.0 \\
8.1\end{array}$ & $\begin{array}{l}5.6 \\
2.9 \\
8.8\end{array}$ & $\begin{array}{l}6.4 \\
5.3 \\
8.5\end{array}$ \\
\hline 3 & $\begin{array}{l}a \\
b \\
c\end{array}$ & $\begin{array}{r}10.3 \\
11.9 \\
7.9\end{array}$ & $\begin{array}{l}5.0 \\
5.2 \\
7.3\end{array}$ & $\begin{array}{r}8.3 \\
17.9 \\
9.2\end{array}$ & $\begin{array}{r}7.9 \\
11.7 \\
8.1\end{array}$ & $\begin{array}{r}5.5 \\
9.2 \\
10.2\end{array}$ & $\begin{array}{l}4.7 \\
7.3 \\
9.2\end{array}$ & $\begin{array}{l}5.1 \\
6.2 \\
8.1\end{array}$ & $\begin{array}{l}5.1 \\
7.6 \\
9.1\end{array}$ \\
\hline 4 & $\begin{array}{l}a \\
b \\
c\end{array}$ & $\begin{array}{l}7.6 \\
8.8 \\
6.7\end{array}$ & $\begin{array}{r}7.6 \\
10.0 \\
14.3\end{array}$ & $\begin{array}{l}5.8 \\
4.0 \\
2.7\end{array}$ & $\begin{array}{l}7.0 \\
7.6 \\
7.9\end{array}$ & $\begin{array}{r}5.1 \\
8.9 \\
11.6\end{array}$ & $\begin{array}{l}5.9 \\
7.2 \\
8.2\end{array}$ & $\begin{array}{l}4.0 \\
6.5 \\
7.2\end{array}$ & $\begin{array}{l}5.0 \\
7.5 \\
9.0\end{array}$ \\
\hline 9 & $\begin{array}{l}\mathrm{a} \\
\mathrm{b} \\
\mathrm{c}\end{array}$ & $\begin{array}{r}10.4 \\
7.6 \\
8.7\end{array}$ & $\begin{array}{r}11.5 \\
8.8 \\
9.5\end{array}$ & $\begin{array}{l}5.2 \\
4.5 \\
9.0\end{array}$ & $\begin{array}{l}9.0 \\
7.0 \\
9.1\end{array}$ & $\begin{array}{r}11.6 \\
5.1 \\
9.1\end{array}$ & $\begin{array}{l}8.9 \\
5.0 \\
8.0\end{array}$ & $\begin{array}{l}4.3 \\
3.3 \\
5.9\end{array}$ & $\begin{array}{l}8.3 \\
4.5 \\
7.7\end{array}$ \\
\hline 10 & $\begin{array}{l}\mathrm{a} \\
\mathrm{b} \\
\mathrm{c}\end{array}$ & $\begin{array}{r}8.3 \\
9.6 \\
10.4\end{array}$ & $\begin{array}{r}2.9 \\
11.2 \\
9.6\end{array}$ & $\begin{array}{r}5.3 \\
10.7 \\
11.9\end{array}$ & $\begin{array}{r}5.5 \\
10.5 \\
10.6\end{array}$ & $\begin{array}{l}4.7 \\
6.2 \\
5.5\end{array}$ & $\begin{array}{l}4.7 \\
6.7 \\
5.9\end{array}$ & $\begin{array}{l}4.7 \\
7.7 \\
5.3\end{array}$ & $\begin{array}{l}4.7 \\
6.9 \\
5.5\end{array}$ \\
\hline \multirow{3}{*}{ Mean } & a & $\begin{array}{r}9.4 \\
\pm 0.4\end{array}$ & $\begin{array}{r}6.8 \\
\pm 0.9\end{array}$ & $\begin{array}{r}6.3 \\
\pm 0.4\end{array}$ & $\begin{array}{r}7.5 \\
\pm 0.4\end{array}$ & $\begin{array}{r}6.4 \\
\pm 0.9\end{array}$ & $\begin{array}{r}6.5 \\
\pm 0.6\end{array}$ & $\begin{array}{r}4.7 \\
\pm 0.2\end{array}$ & $\begin{array}{r}5.9 \\
\pm 0.4\end{array}$ \\
\hline & b & $\begin{array}{r}10.1 \\
\pm 0.6\end{array}$ & $\begin{array}{r}8.6 \\
\pm 0.7\end{array}$ & $\begin{array}{r}9.0 \\
\pm 1.7\end{array}$ & $\begin{array}{r}9.3 \\
\pm 0.6\end{array}$ & $\begin{array}{r}6.9 \\
\pm 0.6\end{array}$ & $\begin{array}{r} \pm 6.8 \\
0.3\end{array}$ & $\begin{array}{r}53 \\
\pm 0.6\end{array}$ & $\begin{array}{r}6.4 \\
\pm 0.4\end{array}$ \\
\hline & c & $\begin{array}{r}10.7 \\
\pm 1.5\end{array}$ & $\begin{array}{r}9.6 \\
\pm 0.9\end{array}$ & $\begin{array}{r}9.7 \\
\pm 1.4\end{array}$ & $\begin{array}{r}10.0 \\
\pm 0.8\end{array}$ & $\begin{array}{r}9.0 \\
\pm 0.7\end{array}$ & $\begin{array}{r}7.9 \\
\pm 0.4\end{array}$ & $\begin{array}{r} \pm 7.1 \\
0.4\end{array}$ & $\begin{array}{r}8.0 \\
\pm 0.4\end{array}$ \\
\hline 1 & $\begin{array}{l}\mathrm{a} \\
\mathrm{b} \\
\mathrm{c}\end{array}$ & $\begin{array}{c}\text { (with } \\
12.0 \\
12.5 \\
14.7\end{array}$ & $\begin{array}{c}\text { t sulph } \\
14.0 \\
13.3 \\
16.1\end{array}$ & $\begin{array}{r}\text { ic acio } \\
9.7 \\
11.5 \\
11.5\end{array}$ & $\begin{array}{l}11.9 \\
12.4 \\
14.1\end{array}$ & $\begin{array}{l}10.3 \\
11.7 \\
10.5\end{array}$ & $\begin{array}{r}11.3 \\
9.2 \\
10.6\end{array}$ & $\begin{array}{r}8.8 \\
10.2 \\
10.3\end{array}$ & $\begin{array}{l}10.1 \\
10.4 \\
10.4\end{array}$ \\
\hline 5 & $\begin{array}{l}a \\
b \\
c\end{array}$ & $\begin{array}{r}3.9 \\
14.2 \\
4.7\end{array}$ & $\begin{array}{r}6.1 \\
8.7 \\
12.6\end{array}$ & $\begin{array}{r}6.8 \\
9.4 \\
11.8\end{array}$ & $\begin{array}{r}5.6 \\
10.8 \\
9.7\end{array}$ & $\begin{array}{r}6.9 \\
6.8 \\
8.2\end{array}$ & $\begin{array}{l}1.1 \\
4.2 \\
8.7\end{array}$ & $\begin{array}{l}3.7 \\
4.8 \\
2.3\end{array}$ & $\begin{array}{l}3.6 \\
5.3 \\
6,4\end{array}$ \\
\hline 6 & $\begin{array}{l}\mathrm{a} \\
\mathrm{b} \\
\mathrm{c}\end{array}$ & $\begin{array}{l}8.3 \\
5.2 \\
9.5\end{array}$ & $\begin{array}{r}6.8 \\
5.5 \\
10.7\end{array}$ & $\begin{array}{l}4.3 \\
5.1 \\
9.2\end{array}$ & $\begin{array}{l}6.5 \\
5.3 \\
9.8\end{array}$ & $\begin{array}{l}6.2 \\
4.3 \\
6.4\end{array}$ & $\begin{array}{l}6.7 \\
3.4 \\
5.8\end{array}$ & $\begin{array}{l}5.7 \\
2.8 \\
4.8\end{array}$ & $\begin{array}{l}6.2 \\
3.5 \\
5.7\end{array}$ \\
\hline 7 & $\begin{array}{l}\text { a } \\
b \\
\text { c }\end{array}$ & $\begin{array}{r}11.5 \\
6.6 \\
11.0\end{array}$ & $\begin{array}{l}5.3 \\
7.2 \\
7.0\end{array}$ & $\begin{array}{l}7.0 \\
7.6 \\
9.1\end{array}$ & $\begin{array}{l}7.9 \\
7.1 \\
9.0\end{array}$ & $\begin{array}{l}3.2 \\
3.4 \\
8.9\end{array}$ & $\begin{array}{r}8.2 \\
5.1 \\
10.9\end{array}$ & $\begin{array}{l}6.1 \\
4.2 \\
9.5\end{array}$ & $\begin{array}{l}5.8 \\
4.2 \\
9.8\end{array}$ \\
\hline 8 & $\begin{array}{l}\text { a } \\
b \\
\text { c }\end{array}$ & $\begin{array}{r}7.2 \\
12.6 \\
18.4\end{array}$ & $\begin{array}{l}5.0 \\
8.3 \\
9.6\end{array}$ & $\begin{array}{r}7.1 \\
7.8 \\
11.3\end{array}$ & $\begin{array}{l}6.4 \\
9.6 \\
9.8\end{array}$ & $\begin{array}{l}6.3 \\
9.1 \\
9.8\end{array}$ & $\begin{array}{l}4.7 \\
6.2 \\
8.0\end{array}$ & $\begin{array}{r}3.7 \\
9.5 \\
18.7\end{array}$ & $\begin{array}{r}4.9 \\
8.3 \\
10.2\end{array}$ \\
\hline & a & $\begin{array}{r}8.6 \\
\pm 1.0\end{array}$ & $\begin{array}{r}7.4 \\
\pm 1.2\end{array}$ & $\begin{array}{r}7.0 \\
\pm 0.6\end{array}$ & $\begin{array}{r}7.7 \\
\pm 0.8\end{array}$ & $\begin{array}{r}6.4 \\
\pm 0.8\end{array}$ & $\begin{array}{r}6.4 \\
\pm 1.2\end{array}$ & $\begin{array}{r}5.6 \\
\pm 0.6\end{array}$ & $\begin{array}{r}6.1 \\
\pm 0.7\end{array}$ \\
\hline Mean & $\mathbf{b}$ & $\begin{array}{r}10.2 \\
\pm 1.2\end{array}$ & $\begin{array}{r}8.6 \\
\pm 0.9\end{array}$ & $\begin{array}{r}8.3 \\
\pm 0.7\end{array}$ & $\begin{array}{r}9.0 \\
\pm 0.9\end{array}$ & $\begin{array}{r}7.1 \\
\pm 1.0\end{array}$ & $\begin{array}{r}5.6 \\
\pm 0.7\end{array}$ & $\begin{array}{r}6.3 \\
\pm 1.0\end{array}$ & $\begin{array}{r}6.3 \\
\pm 0.9\end{array}$ \\
\hline & c & $\begin{array}{r}11.7 \\
\pm 1.6\end{array}$ & $\begin{array}{r}11.2 \\
\pm 1.0\end{array}$ & $\begin{array}{r}10.6 \\
\pm 0.4\end{array}$ & $\begin{array}{r}11.2 \\
\pm 0.7\end{array}$ & $\begin{array}{r}8.8 \\
\pm 0.5\end{array}$ & $\begin{array}{r}8.8 \\
\pm 0.2\end{array}$ & $\begin{array}{r}7.9 \\
\pm 1.3\end{array}$ & $\begin{array}{r}8.5 \\
\pm 0.7\end{array}$ \\
\hline
\end{tabular}


Here again the oxygen consumption of both the cortical and the medullar tissue was the greater, the greater the $p H$ of the medium. There was little difference between the cases with and without $\mathrm{H}_{2} \mathrm{SO}_{4}$ in the side receptacle of the vessel.

The mean $p \mathrm{H}$ of the medium after the manometric measurement was changed in both the cases of cortical and medullar tissue towards the basic side (Table 5).

Table 5.

$p \mathrm{H}$ of Ringer's solution before and after manometric experiment of Tables 3 and 4 .

\begin{tabular}{|c|c|c|c|c|c|c|}
\hline \multirow{2}{*}{ No. } & \multicolumn{2}{|c|}{ a } & \multicolumn{2}{|c|}{ b } & \multicolumn{2}{|c|}{ c } \\
\hline & before & after & before & after & before & after \\
\hline & & & \multicolumn{2}{|c|}{ (Medullar tissue) } & & \\
\hline 1 & 5.266 & 6.755 & 6.817 & 6.934 & 7.335 & 7.488 \\
\hline 2 & 5.578 & 5.966 & 6.908 & 6.939 & 7.438 & 7.516 \\
\hline 3 & 5.552 & 5.987 & 7.034 & 7.047 & 7.327 & 7.243 \\
\hline 4 & 5.270 & 5.811 & 6.812 & 6.722 & 7.268 & 7.660 \\
\hline 5 & 5.634 & 6.876 & 6.926 & 6.944 & 7.444 & 7.570 \\
\hline \multirow[t]{2}{*}{ Mean } & 5.460 & 6.279 & 6.900 & 6.917 & 7.362 & 7.495 \\
\hline & & & \multicolumn{2}{|c|}{ (Cortical tissue) } & & \\
\hline 1 & 5.266 & 6.563 & 6.817 & 6.921 & 7.336 & 7.316 \\
\hline 2 & 5.578 & 6.232 & 6.908 & 6.950 & 7.439 & 7.392 \\
\hline 3 & 5.552 & 6.122 & 7.034 & 7.016 & 7.328 & 7.819 \\
\hline 4 & 5.271 & 5.819 & 6.812 & 6.879 & 7.267 & 7.356 \\
\hline 5 & 5.635 & 5.792 & 6.927 & 7.021 & 7.445 & 7.518 \\
\hline Mean & 5.460 & 6.106 & 6.900 & 6.957 & 7.362 & 7.480 \\
\hline
\end{tabular}

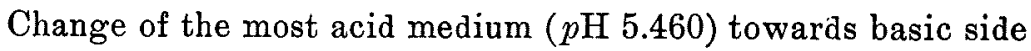
6.279 in the case of medullar tissue, and 6.108 in the case of cortical was the most marked. Change of the more basic medium towards the more basic side was much less marked, and as exceptional cases even the acid change of the original medium was found.

\section{B. Kidney tissue of rabbit.}

It was rather strange to us, that, while the liver tissue of mouse showed the tendency of regulating the $\left[\mathrm{H}^{+}\right]$of the medium in the former experiment, the tissue of kidney, the organ which is generally accepted as one of the chief $\left[\mathrm{H}^{+}\right]$-regulating organs of the body fluid in the body, did not clearly manifest this power.

In this series of experiment, to remove any possible complicating influence, any residue of blood in the kidney was washed out by 
perfusing the whole body with Ringer's solution through jugular vein as in the case of $\mathrm{Okabe}{ }^{15)}$ and the urine constituents in the tissue slices were thoroughly washed out in Ringer's solution. The experimental duration was lengthened one more hour (in all 3 hours) to give the tissue time to manifest sufficient power of the buffer action. Furthermore the $p \mathrm{H}$ range was extended from 5.055 to 7.611, the middle being 6.819 . These $\mathrm{H}^{+}$concentrations were prepared by mixing $5 \mathrm{cc}$. of the phosphate mixture (ratios of mixing primary and secondary phosphate being the same as before) to $100 \mathrm{cc}$. of the normal Ringer's solution.

Oxygen consumption of the cortical and the medullar tissue under the above conditions were as in Table 6 .

\section{Table 6.}

Oxygen consumption of kidney tissue of rabbit in various $p \mathrm{H}-$ Ringer's solution buffered by phosphate mixture $(a=\tilde{5} .1, b=6.8, b=7.6)$.

(1. III.-19. III. 1934)

\begin{tabular}{|c|c|c|c|c|c|c|c|c|c|c|c|c|c|}
\hline \multirow[b]{2}{*}{ No. } & \multirow{2}{*}{$\begin{array}{c}\text { Kind } \\
\text { of } \\
p \mathbf{H}\end{array}$} & \multicolumn{12}{|c|}{ Time (min.) after beginning of observation and Qo } \\
\hline & & $\begin{array}{c}I \\
20\end{array}$ & $\begin{array}{l}\text { II } \\
20\end{array}$ & $\begin{array}{l}\text { III } \\
20\end{array}$ & $\underset{\text { mean }}{\mathrm{I}}$ & $\begin{array}{l}\text { IV } \\
20\end{array}$ & $\begin{array}{c}\mathrm{V} \\
20\end{array}$ & $\begin{array}{l}\text { VI } \\
20\end{array}$ & $\underset{\text { mean }}{\text { II }}$ & $\begin{array}{l}\text { VII } \\
20\end{array}$ & $\begin{array}{c}\text { VIII } \\
20\end{array}$ & $\begin{array}{l}\text { IX } \\
20\end{array}$ & $\underset{\text { mean }}{\text { III }}$ \\
\hline 1 & $\begin{array}{l}a \\
b \\
c\end{array}$ & $\begin{array}{l}8.8 \\
9.0 \\
8.3\end{array}$ & $\begin{array}{l}6.7 \\
9.4 \\
7.9\end{array}$ & $\begin{array}{l}8.7 \\
7.6 \\
5.7\end{array}$ & $\begin{array}{l}8.1 \\
8.7 \\
7.3\end{array}$ & $\begin{array}{r}(1 \\
6.4 \\
7.2 \\
6.5\end{array}$ & $\begin{array}{l}\text { Ledulla } \\
\begin{array}{|r}7.5 \\
7.9 \\
6.3\end{array}\end{array}$ & $\begin{array}{r}\text { ar tiss } \\
\begin{array}{r}6.2 \\
8.4 \\
7.9\end{array}\end{array}$ & $\begin{array}{l}\text { ue) } \\
\begin{array}{r}6.7 \\
7.8 \\
6.9\end{array}\end{array}$ & $\begin{array}{l}4.9 \\
6.6 \\
5.1\end{array}$ & $\begin{array}{l}7.5 \\
5.1 \\
6.2\end{array}$ & $\begin{array}{l}6.0 \\
5.5 \\
4.6\end{array}$ & $\begin{array}{l}6.1 \\
5.7 \\
5.3\end{array}$ \\
\hline 2 & $\begin{array}{l}a \\
b \\
c\end{array}$ & $\begin{array}{r}5.7 \\
9.3 \\
10.3\end{array}$ & $\begin{array}{r}9.6 \\
11.5 \\
10.7\end{array}$ & $\begin{array}{l}5.2 \\
8.0 \\
8.3\end{array}$ & $\begin{array}{l}6.8 \\
9.6 \\
9.8\end{array}$ & $\begin{array}{l}6.6 \\
6.6 \\
9.8\end{array}$ & $\begin{array}{r}7.4 \\
10.8 \\
9.5\end{array}$ & $\begin{array}{r}3.4 \\
5.1 \\
11.0\end{array}$ & $\begin{array}{r}5.8 \\
7.5 \\
10.1\end{array}$ & $\begin{array}{l}6.8 \\
8.0 \\
8.7\end{array}$ & $\begin{array}{l}3.7 \\
7.5 \\
9.8\end{array}$ & $\begin{array}{l}8.4 \\
8.0 \\
9.0\end{array}$ & $\begin{array}{l}6.3 \\
7.8\end{array}$ \\
\hline 3 & $\begin{array}{l}\mathbf{a} \\
\mathbf{b} \\
\mathbf{c}\end{array}$ & $\begin{array}{r}4.3 \\
13.9 \\
7.9\end{array}$ & $\begin{array}{r}4.3 \\
11.7 \\
10.3\end{array}$ & $\begin{array}{r}6.2 \\
8.8 \\
10.4\end{array}$ & $\begin{array}{r}4.9 \\
11.5 \\
9.5\end{array}$ & $\begin{array}{l}5.4 \\
6.7 \\
7.2\end{array}$ & $\begin{array}{l}3.2 \\
7.8 \\
6.9\end{array}$ & $\begin{array}{r}1.9 \\
12.4 \\
7.9\end{array}$ & $\begin{array}{l}3.5 \\
9.0 \\
7.3\end{array}$ & $\begin{array}{r}3.9 \\
11.1 \\
5.4\end{array}$ & $\begin{array}{l}3.9 \\
8.8 \\
6.5\end{array}$ & $\begin{array}{l}3.9 \\
6.0 \\
6.5\end{array}$ & 6.1 \\
\hline 4 & $\begin{array}{l}a \\
b \\
c\end{array}$ & $\begin{array}{r}3.5 \\
14.5 \\
8.8\end{array}$ & $\begin{array}{l}2.5 \\
6.8 \\
8.8\end{array}$ & $\begin{array}{l}3.9 \\
9.7 \\
9.6\end{array}$ & $\begin{array}{r}3.3 \\
10.3 \\
9.1\end{array}$ & $\begin{array}{l}3.5 \\
6.8 \\
8.7\end{array}$ & $\begin{array}{l}4.2 \\
7.9 \\
8.0\end{array}$ & $\begin{array}{l}1.7 \\
4.8 \\
5.8\end{array}$ & $\begin{array}{l}3.1 \\
6.5\end{array}$ & $\begin{array}{l}2.4 \\
8.6 \\
9.6\end{array}$ & $\begin{array}{l}3.5 \\
5.4 \\
5.5\end{array}$ & $\begin{array}{l}2.6 \\
4.8 \\
7.5\end{array}$ & 7.5 \\
\hline 5 & $\begin{array}{l}a \\
b \\
c\end{array}$ & $\begin{array}{l}3.5 \\
8.9 \\
8.3\end{array}$ & $\begin{array}{r}9.0 \\
8.2 \\
11.5\end{array}$ & $\begin{array}{l}5.3 \\
8.5 \\
7.0\end{array}$ & $\begin{array}{l}5.9 \\
8.5 \\
9.2\end{array}$ & $\begin{array}{l}3.3 \\
7.3 \\
8.6\end{array}$ & $\begin{array}{r}3.5 \\
7.9 \\
10.5\end{array}$ & $\begin{array}{l}0.8 \\
7.4 \\
9.5\end{array}$ & 25 & $\begin{array}{l}3.3 \\
6.5 \\
8.2\end{array}$ & $\begin{array}{l}3.9 \\
7.9 \\
7.1\end{array}$ & $\begin{array}{l}3.7 \\
7.6 \\
9.3\end{array}$ & 8.2 \\
\hline 6 & $\begin{array}{l}a \\
b \\
c\end{array}$ & $\begin{array}{r}4.6 \\
14.7 \\
9.1\end{array}$ & $\begin{array}{r}5.8 \\
13.6 \\
7.1\end{array}$ & $\begin{array}{r}6.3 \\
12.6 \\
7.5\end{array}$ & $\begin{array}{r}5.6 \\
13.6 \\
7.9\end{array}$ & $\begin{array}{r}2.9 \\
13.2 \\
7.8\end{array}$ & $\begin{array}{l}3.3 \\
7.8 \\
6.5\end{array}$ & $\begin{array}{r}4.3 \\
10.0 \\
7.0\end{array}$ & $\begin{array}{r}3.5 \\
10.3 \\
7.1\end{array}$ & $\begin{array}{l}3.3 \\
8.8 \\
7.9\end{array}$ & $\begin{array}{l}4.5 \\
8.6 \\
7.3\end{array}$ & $\begin{array}{r}4.4 \\
10.0 \\
6.3\end{array}$ & $\begin{array}{l}4.1 \\
9.1 \\
7.2\end{array}$ \\
\hline & a & $\begin{array}{r}5.1 \\
\pm 0.6\end{array}$ & $\begin{array}{r}6.3 \\
\pm 0.7\end{array}$ & $\begin{array}{r}5.9 \\
\pm 0.4\end{array}$ & $\begin{array}{r}5.8 \\
\pm 0.5\end{array}$ & $\begin{array}{r}4.7 \\
\pm 0.5\end{array}$ & $\begin{array}{r}4.9 \\
\pm 0.6\end{array}$ & $\begin{array}{r}3.1 \\
\pm 0.5\end{array}$ & $\begin{array}{r}4.2 \\
\pm 0.5\end{array}$ & $\begin{array}{r}\mathbf{4 . 1} \\
\pm 0.4\end{array}$ & $\begin{array}{r}4.5 \\
\pm 0.4\end{array}$ & $\begin{array}{r}4.8 \\
\pm 0.6\end{array}$ & $\begin{array}{r}4.5 \\
\pm 0.4\end{array}$ \\
\hline Mean & $\mathrm{b}$ & $\begin{array}{r}11.7 \\
\pm 0.8\end{array}$ & $\begin{array}{r}10.2 \\
\pm 0.6\end{array}$ & $\begin{array}{r}9.2 \\
\pm 0.5\end{array}$ & $\begin{array}{r}10.4 \\
\pm 0.5\end{array}$ & $\begin{array}{r}8.0 \\
\pm 0.7\end{array}$ & $\begin{array}{r}8.4 \\
\pm 0.3\end{array}$ & $\begin{array}{r}8.0 \\
\pm 0.8\end{array}$ & $\begin{array}{r}8.1 \\
\pm 0.4\end{array}$ & $\begin{array}{r}8.3 \\
\pm 0.5\end{array}$ & $\begin{array}{r}7.2 \\
\pm 0.5\end{array}$ & $\begin{array}{r}7.0 \\
\pm 0.5\end{array}$ & $\begin{array}{r}7.5 \\
\pm 0.4\end{array}$ \\
\hline & c & $\begin{array}{r}8.8 \\
\pm 0.2\end{array}$ & $\begin{array}{r}9.8 \\
+0.4\end{array}$ & $\begin{array}{r}8.2 \\
\pm 0.4\end{array}$ & $\begin{array}{r}8.9 \\
\pm 0.3\end{array}$ & $\begin{array}{r}8.1 \\
\pm 0.3\end{array}$ & $\begin{array}{r}7.9 \\
\pm 0.5\end{array}$ & $\begin{array}{r}8.2 \\
\pm 0.5\end{array}$ & $\begin{array}{r}8.1 \\
\pm 0.4\end{array}$ & $\begin{array}{r}7.5 \\
\pm 0.5\end{array}$ & $\begin{array}{r}7.1 \\
\pm 0.4\end{array}$ & $\begin{array}{r}7.2 \\
\pm 0.5\end{array}$ & $\begin{array}{r}7.3 \\
\pm 0.4\end{array}$ \\
\hline
\end{tabular}




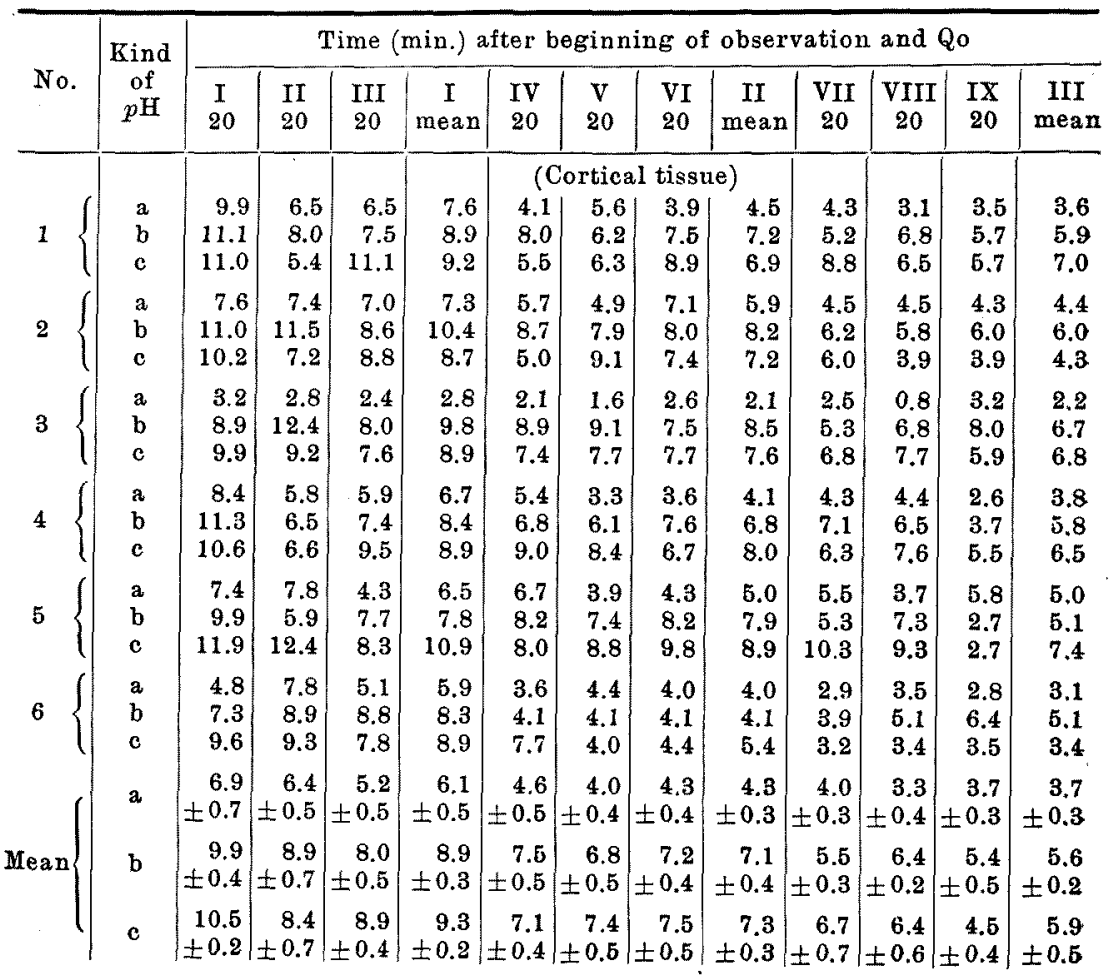

\section{Table 7 .}

$p \mathrm{H}$ of Ringer's solution before and after manometric experiment of Table 6.

\begin{tabular}{|c|c|c|c|c|c|c|}
\hline \multirow{2}{*}{ No. } & \multicolumn{2}{|c|}{$a$} & \multicolumn{2}{|c|}{$\mathbf{b}$} & \multicolumn{2}{|c|}{ c } \\
\hline & before & after & before & after & before & after \\
\hline \multicolumn{7}{|c|}{ (Medullar tissue) } \\
\hline 1 & 4.925 & 5.427 & 6.774 & 6.714 & 7.615 & 7.294 \\
\hline 2 & 5.249 & 5.347 & 6.983 & 6.689 & 7.694 & 7.367 \\
\hline 3 & 4.894 & 5.589 & 6.888 & 6.776 & 6.689 & 7.205 \\
\hline 4 & 5.214 & 5.426 & 6.756 & 7.015 & 7.503 & 7.160 \\
\hline 5 & 5.003 & 5.497 & 6.837 & 7.067 & 7.661 & 7.308 \\
\hline 6 & 5.044 & 5.380 & 6.676 & 6.851 & 7.501 & 7.281 \\
\hline Mean & 5.055 & 5.444 & 6.819 & 6.852 & 7.611 & 7.269 \\
\hline \multicolumn{7}{|c|}{ (Cortical tissue) } \\
\hline 1 & 4.925 & 5.649 & 6.774 & 6.830 & 7.615 & 7.254 \\
\hline 2 & 5.249 & 5.993 & 6.983 & 7.012 & 7.694 & 7.388 \\
\hline 3 & 4.897 & 5.494 & 6.888 & 6.990 & 7.689 & 7.315 \\
\hline 4 & 5.214 & 5.978 & 6.756 & 6.919 & 7.503 & 7.129 \\
\hline 5 & 5.003 & 5.676 & 6.837 & 6.870 & 7.661 & 7.271 \\
\hline 6 & 5.044 & 5.482 & 6.676 & 6.720 & 7.501 & 7.313 \\
\hline Mean & 5.055 & 5.712 & 6.819 & 6.890 & 7.611 & 7.278 \\
\hline
\end{tabular}


Oxygen consumption was again the least at the least $p \mathrm{H}$, but little difference of the consumption was found between 6.819 and 7.611 , the consumption being rather greater in $p \mathrm{H} 6.819$, especially in the case of the medullar tissue, contrary to the result of $\mathrm{Okabe}$ and $\mathrm{Kodama},{ }^{3)}$ which showed the oxygen consumption at $p \mathrm{H} 7.68$ to be greater than that at $p \mathrm{H} 7.02$, though the experimental condition was not identical with ours.

$p \mathrm{H}$ of the medium after the manometric measurement was found to have altered from the original ones (Table 7); the original most acid medium (5.055) having become more basic (5.444 and 5.712 respectively in the case of the medullar tissue and of the cortical), and the original most basic medium (7.611) more acid (7.269 and 7.278 respectively in the case of the medullar and of the cortical). The most neutral medium (6.819) suffered much less change, having become a little more basic.

\section{Oxygen Consumption and Carbon Dioxide} Output of Kidney Tissue of Rabbit.

In the former experiment the $p \mathrm{H}$ of the medium, in which the tissue slices were kept for a few hours during the experiment, was prepared by phosphate mixtures. That the tissue respiration of some tissue was not in the optimum condition in such medium with phosphate mixtures, was clearly shown in the previous report. ${ }^{1)}$ The buffer potency of the tissue, if it existed, might not be in an adequate condition in such medium to manifest its sufficient action. It was desirous to examine the buffer potency in a more physiologically adequate medium.

This was the next attempt to be reported in the following. The $p \mathrm{H}$ of the Ringer's solution was prepared by sodium bicarbonate saturated with carbon dioxide of suitable tension, both being the most important factors in maintaining physiologically the $\left[\mathrm{H}^{+}\right]$of the body fluid.

In all the experiments $1 \mathrm{n}$ sulphuric acid was kept in the side receptacle of the experimental vessel to absorb any trace of ammonia if expelled from the liquid medium.

The first series of experiment was measurement of the tissue respiration (Qo and Qc) of the kidney tissue (cortical and medullar) in $p \mathrm{H} 6.1$ (Table 8). The $p \mathrm{H}$ of the medium was so prepared that to $100 \mathrm{cc}$. of Ringer's solution, $1 \mathrm{cc}$. of $1 \% \mathrm{NaHCO}_{3}$-solution was added, 
$\mathrm{CO}_{2}$-tension being $5 \%$ in oxygen. Calculation of the $p \mathrm{H}$ of the medium gives about 6.1.

Oxygen consumption and carbon dioxide output were generally smaller compared with those in the former series of experiment, especially in the case of medullar tissue. The latter showed often positive value of $Q_{0}$ and negative one of $Q c$, which is quite absurd, and had to result from experimental error. At the calculation of the mean these absurd values were taken as zero.

Table 8.

Oxygen consumption $(Q \circ)$ and carbon dioxide output $(Q c)$ of kidney tissue of rabbit in Ringer's solution of $p \mathrm{H} 6.0$ buffered by carbon dioxide-bicarbonate.

(25. VII. 31. VII. 1934)

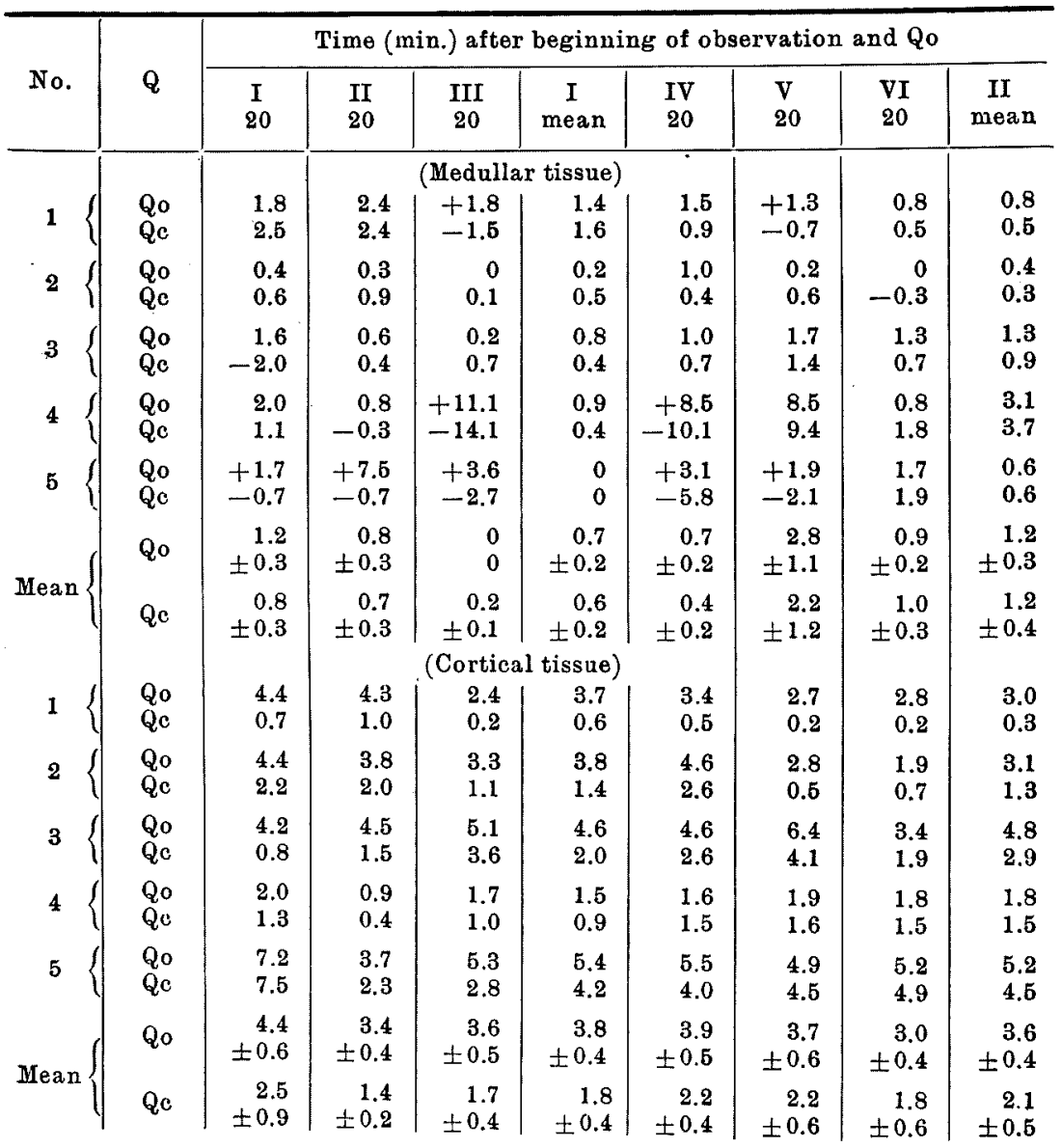


The amount of carbon dioxide output was smaller than that of oxygen consumption in both cases of the cortex and medulla.

$p \mathrm{H}$ of the Rin-

ger's solution in the thermo-barometric manometer vessel after manometric experiment was potentiometrically 6.045 (instead of calculated value 6.1 ), and that of the experimental vessel with cortical tissue 6.359 and that

Table 9 $p \mathrm{H}$ of Ringer's solution before and after manometric experiment of Table 8.

\begin{tabular}{c|c|c|c|c}
\hline \multirow{2}{*}{ No. } & \multicolumn{4}{|c}{$p \mathrm{H}$} \\
\cline { 2 - 5 } & Control & Medullar & Control & Cortical \\
\hline & & & & \\
1 & 6.070 & 6.128 & 6.005 & 6.127 \\
2 & 6.026 & 6.268 & 6.014 & 6.469 \\
3 & 6.164 & 6.395 & 6.114 & 6.542 \\
4 & 6.061 & 6.081 & 6.077 & 6.515 \\
5 & 6.004 & 6.413 & 6.016 & 6.144 \\
Mean & 6.065 & 6.257 & 6.045 & 6.359
\end{tabular}

with medullar tissue 6.257 , that is, the original acid medium is changed towards the more basic side, namely towards the neutral point.

In the next series, the tissue respiration was measured in the medium of $p \mathrm{H} 8.1$, which was prepared by adding 2 cc. of $5 \% \mathrm{NaHCO}_{3}$ solution to $100 \mathrm{cc}$. of the normal Ringer's solution, and by saturating the mixture with $0.5 \% \mathrm{CO}_{2}$-gas (Table 10 ).

Table 10.

Oxygen consumption (Qo) and carbon dioxide output (Qo) of kidney tissue of rabbit in Ringer's solution of $p \mathrm{H} 8.1$ buffered by carbon dioxide-bicarbonate.

(2. VIII.-7. VIII. 1934)

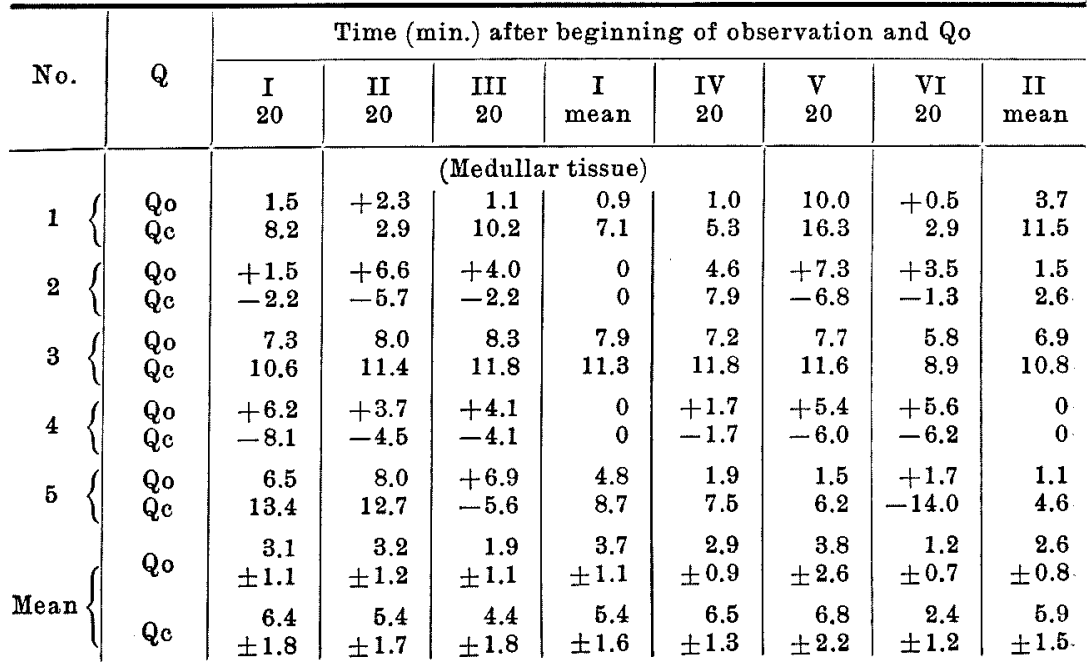




\begin{tabular}{|c|c|c|c|c|c|c|c|c|c|}
\hline \multirow[b]{2}{*}{ No. } & \multirow[b]{2}{*}{ Q } & \multicolumn{8}{|c|}{ Time (min.) after beginning of observation and Qo } \\
\hline & & $\begin{array}{c}\text { I } \\
20\end{array}$ & $\begin{array}{l}\text { II } \\
20\end{array}$ & $\begin{array}{l}\text { III } \\
20\end{array}$ & $\underset{\text { mean }}{\mathbf{I}}$ & $\begin{array}{l}\text { IV } \\
20\end{array}$ & $\begin{array}{c}\mathrm{V} \\
20\end{array}$ & $\begin{array}{l}\text { VI } \\
20\end{array}$ & $\underset{\text { mean }}{\text { II }}$ \\
\hline & & & \multicolumn{4}{|c|}{ (Cortical tissue) } & & & \\
\hline 1 & $\begin{array}{l}\text { Qo } \\
\text { Qc }\end{array}$ & $\begin{array}{r}3.6 \\
-0.8\end{array}$ & $\begin{array}{r}2.0 \\
-0.3\end{array}$ & $\begin{array}{l}6.2 \\
5.4\end{array}$ & $\begin{array}{l}3.9 \\
1.8\end{array}$ & $\begin{array}{l}4.9 \\
3.5\end{array}$ & $\begin{array}{l}3.3 \\
1.1\end{array}$ & $\begin{array}{l}3.3 \\
1.8\end{array}$ & $\begin{array}{l}3.8 \\
2.1\end{array}$ \\
\hline 2 & $\begin{array}{l}\text { Qo } \\
\text { Qc }\end{array}$ & $\begin{array}{l}2.5 \\
1.1\end{array}$ & $\begin{array}{l}2.4 \\
0.5\end{array}$ & $\begin{array}{l}2.5 \\
1.8\end{array}$ & $\begin{array}{l}2.5 \\
1.1\end{array}$ & $\begin{array}{l}3.0 \\
1.1\end{array}$ & $\begin{array}{l}3.8 \\
2.4\end{array}$ & $\begin{array}{r}0.3 \\
-1.6\end{array}$ & $\begin{array}{l}2.4 \\
1.2\end{array}$ \\
\hline 3 & $\begin{array}{l}\text { Qo } \\
\text { Qe }\end{array}$ & $\begin{array}{l}5.9 \\
3.0\end{array}$ & $\begin{array}{l}7.1 \\
3.5\end{array}$ & $\begin{array}{l}5.0 \\
2.2\end{array}$ & $\begin{array}{l}6.0 \\
2.9\end{array}$ & $\begin{array}{l}3.1 \\
4.1\end{array}$ & $\begin{array}{l}5.1 \\
2.2\end{array}$ & $\begin{array}{l}5.8 \\
4.0\end{array}$ & $\begin{array}{l}4.7 \\
3.4\end{array}$ \\
\hline 4 & $\begin{array}{l}\text { Qo } \\
\text { Qc }\end{array}$ & $\begin{array}{l}3.4 \\
1.5\end{array}$ & $\begin{array}{l}2.8 \\
2.2\end{array}$ & $\begin{array}{l}3.6 \\
3.0\end{array}$ & $\begin{array}{l}3.3 \\
2.2\end{array}$ & $\begin{array}{l}3.1 \\
2.8\end{array}$ & $\begin{array}{l}3.6 \\
2.7\end{array}$ & $\begin{array}{l}5.5 \\
6.1\end{array}$ & $\begin{array}{l}4.1 \\
3.9\end{array}$ \\
\hline 5 & $\begin{array}{l}\text { Qo } \\
\text { Qc }\end{array}$ & $\begin{array}{r}0.2 \\
-3.1\end{array}$ & $\begin{array}{l}5.3 \\
3.9\end{array}$ & $\begin{array}{r}0 \\
-2.0\end{array}$ & $\begin{array}{l}1.8 \\
1.3\end{array}$ & $\begin{array}{l}8.6 \\
0.7\end{array}$ & $\begin{array}{l}3.1 \\
0.9\end{array}$ & $\begin{array}{l}4.2 \\
2.6\end{array}$ & $\begin{array}{l}5.3 \\
1.4\end{array}$ \\
\hline & Qo & $\begin{array}{r}3.1 \\
\pm 0.6\end{array}$ & $\begin{array}{r}3.9 \\
\pm 0.7\end{array}$ & $\begin{array}{r}3.5 \\
\pm 0.7\end{array}$ & $\begin{array}{r}3.5 \\
\pm 0.5\end{array}$ & $\begin{array}{r}4.5 \\
\pm 0.7\end{array}$ & $\begin{array}{r}3.8 \\
\pm 0.2\end{array}$ & $\begin{array}{r}3.8 \\
\pm 0.7\end{array}$ & $\begin{array}{r}4.1 \\
\pm 0.3\end{array}$ \\
\hline Mean & Qc & $\begin{array}{r}1.1 \\
\pm 0.4\end{array}$ & $\begin{array}{r}2.0 \\
\pm 0.5\end{array}$ & $\begin{array}{r}2.5 \\
\pm 0.6\end{array}$ & $\begin{array}{r}1.9 \\
\pm 0.2\end{array}$ & $\begin{array}{r}2.4 \\
\pm 0.4\end{array}$ & $\begin{array}{r}1.9 \\
\pm 0.2\end{array}$ & $\begin{array}{r}2.9 \\
+0.7\end{array}$ & $\begin{array}{r}2.4 \\
+0.4\end{array}$ \\
\hline
\end{tabular}

Oxygen consumption and carbon dioxide output of the cortical tissue were in this case little different from that of the first case. Amount of the carbon dioxide was smaller than that of the oxygen consumption.

Oxygen consumption and carbon dioxide output of the medullar tissue were in this case greater than those of the first series, showing again in some cases positive value of $Q o$ and negative of $Q c$, which were regarded as zero in the calculation of the mean as before. It is to be noticed that the amount of carbon dioxide output was much greater than that of the oxygen consumption. This result seems to indorse the view stated in the former report $(3, \mathrm{p}$. 276 ), that "the buffer action of the medullar tissue against lowering

Table 11.

$p \mathrm{H}$ of Ringer's solution before and after manometric experiment of Table 10.

\begin{tabular}{c|c|c|c|c}
\hline \multirow{2}{*}{ No. } & \multicolumn{4}{|c}{$p \mathrm{H}$} \\
\cline { 2 - 5 } & Control & Medullar & Control & Cortical \\
\hline 1 & 8.331 & 8.177 & 8.319 & 8.241 \\
2 & 8.168 & 8.151 & 8.203 & 7.622 \\
3 & 8.107 & 8.067 & 8.199 & 8.153 \\
4 & 8.192 & 8.123 & 8.191 & 8.141 \\
5 & 8.177 & 8.002 & 8.137 & 8.005 \\
Mean & 8.195 & 8.104 & 8.209 & 8.032
\end{tabular}
of the hydrogen ion concentration of the medium would be partly attributed to a glycolysis of the tissue......"

Actual change of the medium towards the physiological reaction was not marked (Table 11); the $p \mathrm{H}$ 
of the medium after 2 hours' manometric experiment was 8.104 against the $p \mathrm{H}$ of the control vessel 8.195. Change of the $p \mathrm{H}$ was rather marked in the case of cortical tissue; against the $p H$ 8.104 of the control vessel was that of the experimental vessel 8.032.

It would be naturally inadequate to compare the amount of the respiration in our case with that of $\Theta \mathrm{kabe}$ and $\mathrm{Koda} \mathrm{ma},{ }^{3}$ ) though the experimental conditions were on the whole identical except the $p \mathrm{H}$ value experimented with. But if it be allowed to treat them together, then the optimum $p \mathrm{H}$ for the respiration of the kidney tissue may be assumed to exist between 7.68 and 8.2.

\section{Discussion.}

Oxygen consumption of liver tissue of mouse and kidney tissue of rabbit in bicarbonate- and carbon dioxide-free Ringer's solution increased on the whole with increase of the $p \mathrm{H}$ of the medium by phosphate mixture within the range between 5.460 and 7.362. This result coincides with those of earlier investigators. ${ }^{\$}$ At greater $p \mathrm{H}$ (7.611) we found no parallel increase of the oxygen consumption, in the case of medullar tissue even a decrease, while the earlier investigators found increased oxygen consumption with increase of $p \mathrm{H}$ till somewhat greater than 8.0.

Kis $\mathrm{h}$ and Leibowitz ${ }^{16}$ ) found a decreased oxygen consumption of kidney tissue of marmot at $p H$ 8.1. The discrepancy may be due to difference of experimental conditions or to the tissue used.

Recently $\mathrm{Ha} \mathrm{mana} \mathrm{ka}{ }^{17}$ ) reported the influence of $\left[\mathrm{H}^{+}\right]$on the oxygen consumption of kidney and cerebral cortex tissue of white rat, between $p \mathrm{H} 5.2$ and 8.0. He found the optimum $p \mathrm{H}$ for the kidney tissue at 7.4, that for the cerebral cortex at 6.8 to 8.0. The general tendency of change of the oxygen consumption of the kidney tissue by change of $p \mathrm{H}$ seems to be identical with ours, at greater $p \mathrm{H}(8.0)$ showing a decrease. But the absolute value of the oxygen consumption in his case is much greater than ours, the difference being perhaps due to the difference of the experimental condition. Hamanak a seems to have used the solution of phosphate mixture as the medium, without adding it to Ring er's solution.

Oxygen consumption and carbon dioxide output of kidney tissue in bicarbonate- carbon dioxide-Ring e r's solution were measured only at two limited $p \mathrm{H}$ 6.0 and 8.2. And those between these limitations are not known. But if we take the result of $\mathrm{Okabe}$ and $\mathrm{Kodama}$, experimental condition of which were on the whole quite identical with ours, in consideration together with

§ References may be found in $O \mathrm{kabe}$ and $\mathrm{K}$ od a ma's paper (3).

16) K is ch, B. and J. Leib ow itz, Biochem. Z, 1930, 220, 105.

17) H a manaka, N., Kyôtohuritu Ika Daig. Z., 1936, $18,1$. 
ours, then the oxygen consumption and the carbon dioxide output in our case at $p \mathrm{H} 6.0$ show a decrease, but not so small as the calculated ralues of the straight lines requires. Those at $p \mathrm{H} 8.2$ are much smaller than those at 7.68 in $\mathrm{Okabe}$ and Kodama's case. It seems to be that the oxygen consumption and carbon dioxide output decreases rapidly at greater $p \mathrm{H}$, somewhere about 8.0.

The fact seems, at any rate, to be established, that the oxygen consumption and the carbon dioxide output of liver tissue of mouse and kidney tissue of rabbit increases with increase of $p H$ of the medium within the range between about 5.5 and 8.0. The discrepancy of the result in bicarbonate- free medium with $p H 7.6$ with the above might be due to the difference of the experimental condition, the tissue in phosphate mixture being, perhaps, injured in some way.

On the whole change of the oxygen consumption of the kidney tissue by change of the $p \mathrm{H}$ was not remarkable in the case of bicabonate- free Ringer's solution, compared with that of bicarbonateRinger, which is more physiological than the former. That is, in the physiological condition the tissue respiration seems to react more sensitively upon the change of the milieu.

Increased oxygen consumption and carbon dioxide output at greater $p \mathrm{H}$ can be considered to have some relationship with the buffer action of the tissue, because the increase of the metabolic products can naturally neutralize the basic medium. Now we will proceed with our discussion on the buffer potency of the tissue.

The $p H$ of Ringer's solution with range 5.460 to 7.362 , which was prepared by phosphate mixture, changed after two hours' manometric experiment on kidney tissue towards basic side with few exceptions at greater $p \mathrm{H}$, while in the case of liver tissue of mouse the medium changed its $p \mathrm{H}$ towards a middle point, which lies presumably at about 6.7. Little difference could be found between the cortical and the medullar tissue. We see here that some kinds of tissue can change the $p \mathrm{H}$ of the medium to a certain extent in which it bathe, and the point towards which the reaction is to be changed, is different according to the kind of tissue.

In the case of three hours' manometric experiment, change of the medium from greater $p \mathrm{H}$ towards acid side appeared distinctly both on the cortical and the medullar tissue, the point of converging being somewhere about 6.9. Discrepancy between this result and that of the former series may be attributed to some differences of experimental conditions, especially the period, during which the tissue bathed in the medium for manometric experiment. 
In carbon dioxide-bicarbonate Ringe r's solution the kidney tissue, cortical and medullar, manifested the power to convert the acid medium towards the basic side and the basic one towards the acid, though it was less marked in the case of medullar tissue at greater $p \mathrm{H}$.

In the above argument, influence of the carbon dioxide liberated by the tissue on $p \mathrm{H}$ of the medium was disregarded. This will now be taken into consideration.

The difference between the $p \mathrm{H}_{1}$ of the Ringer's solution in the control vessel and the $p \mathrm{H}_{2}$ of the medium in which tissue bathed during two hours can be expressed as following:

$$
\begin{aligned}
p \mathrm{H}_{1}-p \mathrm{H}_{2} & =\left\{p \mathrm{~K}_{1}+\log \frac{\left[\mathrm{NaHCO}_{3}\right]}{\left[\mathrm{CO}_{2}\right]}\right\} \\
& -\left\{p \mathrm{~K}_{1}+\log \frac{\left[\mathrm{NaHCO}_{3}\right]}{\left[\mathrm{CO}_{2}\right]+[\mathrm{Xc}]}\right\} \\
& =\log \frac{\left[\mathrm{CO}_{2}\right]+[\mathrm{Xc}]}{\left[\mathrm{CO}_{2}\right]}
\end{aligned}
$$

where $\left[\mathrm{CO}_{2}\right]$ means carbon dioxide tension in experimental vessel expressed in volume $\%$ i.e. $1.5 \%$ in one series and $5 \%$ in the other series, and $[\mathrm{Xc}]$ means the increase of the volume $\%$ of the carbon dioxide liberated by the tissue. In one example $79.2 \mathrm{cmm}$. carbon dioxide was liberated in a gas space of $10.53 \mathrm{cc}$. for 2 hours. If the amount of bicarbonate after the manometric experiment be taken, for convenience' sake, as the same as that before the experiment, then the increase of the carbon dioxide can be expressed as $79.2 \times 100 \div$ $10530=0.75 \%$. Applying this value to the above mentioned formula, the difference of $p \mathrm{H}\left(p \mathrm{H}_{1}-p \mathrm{H}_{2}\right)$ becomes 0.397 in the case of 1.5 volume $\%$ of carbon dioxide, and 0.060 in the case of $5 \%$. Influence of the liberated carbon dioxide on the $p \mathrm{H}$ of the medium is, therefore, as a matter of course, more distinct in the case of the basic medium, i.e. of low carbon dioxide tension. These extra $p \mathrm{H}$ must be reduced from the values mentioned in the tables as regulated $p \mathrm{H}$, because the latter was measured potentiometrically in such a condition as if the medium had received no increase of carbon dioxide tension.

Though the power to convert the $p \mathrm{H}$ of the medium seems not to have been sufficiently manifested,- - which fact was perhaps partly due to a minor amount of tissue compared with that of the liquid me- 
dium)-existence of the buffer potency of liver tissue of mouse and of kidney tissue of rabbit seems to have been established.

The tissue respiration had to take place, then, not under the $p \mathrm{H}$ of the medium, which had been freshly prepared, but under somewhat modified $p \mathrm{H}$.

In what way the power of the buffer action should be expressed, is a problem to be considered. It may be suitable to adopt a method which Atzler and Lehmann used (7, p. 210), but it is to be regretted that in the present experiment no such measurement has been attempted.

Finally some consideration may be given to the mechanismus of the buffer potency of tissue.

The first thing which occurs to our mind is the transfer of $\mathrm{HCl}$ between plasma and blood corpuscles, at carbon dioxide saturation, which was first assumed by Gürber ${ }^{18)}$ and verified later partly by Van Slyke and Cullen. ${ }^{19}$

$\mathrm{Ha} \mathrm{mburger} \mathrm{r}^{20)}$ found also transfer of kalium between blood corpuscle and plasma under carbon dioxide saturation. He seems to consider this phenomenon as one of the properties of all tissue cells. Henders on and $\mathrm{Haggard}{ }^{21)}$ assumed also such alkali transfer from tissue to blood under increased $\mathrm{CO}_{2}$ tension of blood, without any experimental verification. $\mathrm{Fenn}$ and $\mathrm{Cob} \mathrm{b}^{22}$ have recently proved that assumption experimentally with frog muscle.

If such transfer of electrolytes (anion or cation, or both) between tissue cells and the surrounding medium can occur, then it is a matter of course that the $p$ H-regulating ability of the medium by tissue exists.

Goldenberg ${ }^{23}$ reported also a combining of $\mathrm{H}$ - and $\mathrm{OH}$-ion by nervous tissue in physiological $\mathrm{NaCl}$-solution at various $p \mathrm{H}$.

Literary survey on the buffer potency in the tissue cell itself, (for instance of $\mathrm{Hill},{ }^{24)} \mathrm{Okune} \mathrm{f}^{25} \ldots \ldots$ ), other than the power of regulating the $p \mathrm{H}$ of the surrounding medium by the tissue cell, will not be here carried out.

As our further experiment any actual shift of electrolytes between tissue cells and the surrounding medium it is hoped will be investigated in vitro, in connection with buffer potency of tissue cells and also with tissue respiration.

\section{Summary.}

Influence of hydrogen ion concentration of the medium on the

18) Gür ber, A., Maly's Jahresber. Fortschr. Tierchem., 1895, 25, 165.

19) Van Slyke, D.D., and G.E. Cullen, J. Biol. Chem., 1917, 30, 303.

20) H a mburger, H.J., Wiener Med. W., 1916, 66, 519, 575.

21) He nderso $\mathrm{n}, \mathrm{Y}$. and H. W. Haggard, J. Biol. Chem., 1918, 33, 344.

22) F e n n, W.O. and D.M. C o b b, Am. J. Physiol., 1935, 112, 41. 534.

23) Golden berg, E.E., Fiziol. Z., 1935, 18, 441, cit from Ber. Physiol, 1935, 88, 96, 439 .

24) Hill, A.V., C.N.H. Long and H. Lupto n, Proc. Roy. Soc., London, B, 1924,

25) $0 \mathrm{kuneff}$, N., Biochem, Z., 1930, 220, 164. 
liver tissue of mouse, chiefly on the kidney tissue of rabbit was investigated, attention being specially paid to the buffer potency of the tissue, that is, power of regulating the hydrogen ion concentration of the surrounding medium by the tissue cell.

Method for tissue respiration was that of W a r bu rg $(1923,1924)$.

Hydrogen ion concentration of Ringer's solution was potentiometrically measured before and after the manometric measurement.

(1) Oxygen consumption of liver tissue of mouse was greater, the greater the $p \mathrm{H}$ was between 5.664 and 7.438 .

The $p \mathrm{H}$ of the Ringer's solution increased on acid side and decreased on basic side.

(2) Oxygen consumption of kidney tissue of rabbit, both cortical and medullar, was greater the greater the $p \mathrm{H}$ was between 5.055 and 6.900 , and that at 7.611 was not different from that at 6.819 .

The $p \mathrm{H}$ of the medium (5.460-7.363) increased after 2 hours' manometric experiment, and in the case of 3 hours' experiment, the acid medium (5.055-6.819) became more basic and the basic medium more acid.

(3) Oxygen consumption and carbon dioxide output of kidney tissue in $\mathrm{CO}_{2}$ - bicarbonate $\mathrm{Ringer}$ 's solution with acid $p \mathrm{H}(6.1)$ and basic $p \mathrm{H}$ (8.2) was much smaller than those in the bicarbonate free Ringer's solution buffered with phosphate mixture.

The Ringer's solution shifted its acid $p H$ towards basic side and the basic $p H$ towards acid side. 